\title{
Investigating the Relationship between Porosity and Permeability Coefficient for Pervious Concrete Pavement by Statistical Modelling
}

\author{
Hassan Tajik Ghashghaei, Abolfazl Hassani* \\ Parand Islamic Azad University, Tarbiat Modares University, Tehran, Iran \\ Email: "hassani@modares.ac.ir
}

Received 22 October 2015; accepted 26 February 2016; published 29 February 2016

Copyright @ 2016 by authors and Scientific Research Publishing Inc.

This work is licensed under the Creative Commons Attribution International License (CC BY). http://creativecommons.org/licenses/by/4.0/

\section{(c) (i) Open Access}

\begin{abstract}
A study evaluating the relationship between porosity and permeability coefficient for pervious concrete (PC) is presented. In addition, the effect of mixture design parameters particularly, water-to-cement ratio (W/C) and size of aggregate on the permeability coefficient of PC was investigated. The PC mixtures were made with 4 range of $W / C$ and 2 range size of aggregate. PC mixes were made from each aggregate and were tested. The results showed that the $\mathrm{W} / \mathrm{C}$ and aggregate size are key parameters which significantly affect the characteristic performance of PC. Permeability coefficient of coarse pervious concrete (CPC) is bigger than fine pervious concrete (FPC) and the porosity of CPC are bigger than porosity of FPC. A regression model (RM) along with analysis of variance (ANOVA) was conducted to study the significance of porosity distribution on permeability coefficient of PC. The statistical model developed in this study can facilitate prediction permeability coefficient of CPC and FPC as the sustainable pavements.
\end{abstract}

\section{Keywords}

Pervious Concrete, W/C, Porosity, Permeability Coefficient

\section{Introduction}

A special type of concrete pavement characterized by an interconnected pore structure and high void content in the range of $15 \%-35 \%$ is pervious concrete (PC), thus allowing infiltration of water through its structure [1].

${ }^{*}$ Corresponding author.

How to cite this paper: Ghashghaei, H.T. and Hassani, A. (2016) Investigating the Relationship between Porosity and Permeability Coefficient for Pervious Concrete Pavement by Statistical Modelling. Materials Sciences and Applications, 7, 101107. http://dx.doi.org/10.4236/msa.2016.72010 
While its constituent materials are similar to that of normal concrete, PC contains little or no fine aggregate. It is also known as permeable concrete, porous concrete and no-fine concrete. PC has been used in low-traffic pavements such as parking lots and sidewalks [2]. Permeability coefficient or hydraulic conductivity is the most important performance characteristic of PCs, and with any some material, transport properties are dependent on the pore structure features [3]. PC allows water to pass through its structure due to an increased air voids network. This open structure gives this concrete the added possibility to be applied in pavement engineering as a water drainage layer [4]. The costs of such asphalt pavements will grow the coming years due to the foreseeable increase in oil prices. PC is therefore a suitable material to be considered for increased usage in the developing sustainable pavement [5]. Natural Resources are increasingly consumed due to rapid urbanization and thereafter human construction activities, so that various strategies are being investigated by engineers to protect and restore natural ecosystems in the world. PC pavement is termed as comprising materials that facilitate storm water infiltrate and transfer to the underlying subsoil [6]. The porosity is the ratio of the Volume of Voids to the total Volume of the Specimen. Some of the voids in PC are not effective in Carrying water through the material. The Voids that are frequently called the "effective void” are important. Some methods for finding the porosity of PC only calculate the effective voids. Some researchers recommends to finding the total porosity of PC using a water displacement method [7]. The water displacement method is based on Archimedes principle of buoyancy, which states that the buoyancy force is equal to the weight of fluids displaced. The dry mass, the submerged mass and the total volume must be known to calculate the porosity using the water displacement method [8]. Since the permeability coefficient of PC is the most important characteristic of PC, in this study, the characteristic of PC has been evaluated. It's believed that PC can effectively assist solving drainage problems and reducing the risk of flash flooding, resulting from continuous urban development [9].

One of the most important parameters for PC that affects the performance is porosity. PC made with different porosity has different permeability coefficient. In this study a statistical modelling approach was used to determine the effect of porosity on permeability coefficient of PC. Based on the experimental results, statistical modelling was used to investigate PC properties.

\section{Experimental Program}

For each mixture, triplicates of $100 \times 200 \mathrm{~mm}$ cylinders were prepared in three layers, respectively with each layer tamped 15 times using a standard compacting bar. Excessive tamping was avoided in order to prevent blockage of the PC open pore structure. Excess concrete above the upper edge of the mold was removed and a steel trowel was used to press on the surface for levelling.

A total of 24 PC mixtures were prepared and tested. All mixtures were designed with single sizes of crushed silica aggregates. The single size of aggregate defined as the size of sieve on which, $100 \%$ of aggregate was passed but all retained the sieve under that. Crushed silica Aggregates with a size of 4.75 - $9.5 \mathrm{~mm}$ and 9.5 $19.5 \mathrm{~mm}$ were used in this study. Aggregates with a size of 4.75 - $9.5 \mathrm{~mm}$ were named fine and aggregates with a size of 9.5 - $19.5 \mathrm{~mm}$ were named coarse. The engineering properties of used aggregates are shown in Table 1. Type 2 Portland cement having a specific gravity of 3.15 and conforming to the requirements of ASTM C 150, was used for preparing all the PC mixtures. The properties of type 2 cement are shown in Table 2.

All mixtures were produced using single size aggregate and only Portland cement and W/C of 0.28, 0.3, 0.32, and 0.34. $1400 \mathrm{~kg}$ aggregates were used for making one cubic meter of PC mixes. PC mixes was made from fine

Table 1. Engineering properties of aggregates.

\begin{tabular}{cccc}
\hline Flakiness Index (\%) & Water absorption (\%) & Los Angeles Abrasion (\%) & Sand Equivalent (\%) \\
\hline 10 & 3 & 13 & 70 \\
\hline
\end{tabular}

Table 2. Properties of Type 2 cement, according to ASTM C150.

\begin{tabular}{|c|c|c|c|c|c|c|c|c|c|c|}
\hline & \multicolumn{3}{|c|}{ Chemical properties } & \multirow{2}{*}{$\begin{array}{l}\text { Blaine specific } \\
\text { surface } \mathrm{cm}^{2} / \mathrm{g}\end{array}$} & \multirow{2}{*}{$\begin{array}{c}\text { Autoclave } \\
\text { expansion, \% }\end{array}$} & \multicolumn{2}{|c|}{$\begin{array}{l}\text { Physical properties } \\
\text { Setting time }\end{array}$} & \multicolumn{3}{|c|}{ Compressive strength $\mathrm{MPa}$} \\
\hline & Mg O \% & L.O.I \% & I.R \% & & & $\begin{array}{l}\text { Initial } \\
\text { minutes }\end{array}$ & Final hours & 3-day & $\begin{array}{l}\text { At least } 7 \\
\text { days }\end{array}$ & $\begin{array}{c}\text { At last } 28 \\
\text { days }\end{array}$ \\
\hline Value & $<6$ & $<3$ & $<0.75$ & $>2800$ & $<0.8$ & $>45$ & $<6$ & $>10$ & $>17$ & $>21$ \\
\hline
\end{tabular}


aggregates was named fine pervious concrete (FPC), and PC mixes was made from coarse aggregates was named coarse pervious concrete (CPC).

All Mixtures were proportioned to achieve appropriate permeability coefficient and porosity. All concrete specimens were prepared in accordance with "standard practice for making and curing concrete test specimens in the laboratory" [10].

Standard $100 \mathrm{~mm} \times 200 \mathrm{~mm}$ diameter cylinders were used for water permeability coefficient tests on hardened PC. All specimens were de-molded after $24 \mathrm{~h}$ and stored in the curing room at $95 \%$ relative humidity. The permeability coefficient was reported based on the average of three samples. Picture of PC sample is shown in Figure 1.

The permeability coefficient test was measured using the falling head method. Permeability coefficient was calculated using Darcy's law as gives below:

$$
k=\frac{A_{1} l}{A_{2} t} \log \frac{h_{1}}{h_{2}}
$$

where $A_{1}$ and $A_{2}$ are the cross-sectional areas of the sample and the tube respectively, and $L$ is the length of the specimen for typical specimen geometry, $h_{1}$ and $h_{2}$ is the initial and final heads of water and $t$ is the time between transition water from $h_{1}$ to $h_{2}$. Picture of permeability coefficient test kit is shown in Figure 2.

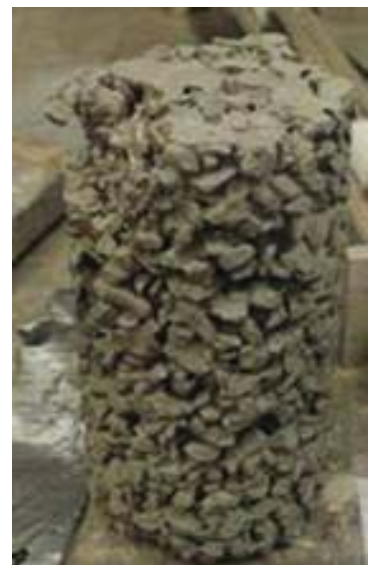

Figure 1. Picture of PC sample.

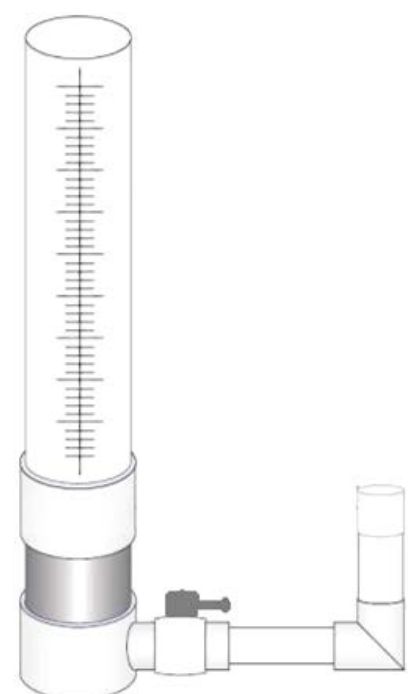

Figure 2. Falling head method kit for permeability coefficient measurement. 
The specimens were enclosed in a mold that was lined with a thin rubber sheet, and tightened with hose clamps to minimize any flow along the sides of the mold that would affect the measurement of permeability coefficient. The sample was then connected to a vertical PVC pipe on both the upstream and downstream sides.

The apparatus was filled with water from the downstream end, to expel any air voids that may have been present in the PC sample. Once water head reached the top of the specimen, the apparatus was then filled from the upstream side. The system was allowed to reach equilibrium, at which time the water level was recorded, representing the head level on the downstream side.

Maintaining the constant downstream head at a higher elevation than top of the PC sample provided full saturation throughout the test. The upstream water level was then increased to a height of $30 \mathrm{~cm}$ and the valve closed. The valve was then opened and water allowed to fall to a height of $10 \mathrm{~cm}$, during which the time it look for the water level to fall was recorded. This head difference was expected to maintain laminar flow for the range of anticipated permeability coefficient.

The total porosity was measured by finding the difference of the PC sample cylinder weight submerged in the water and the weight after air drying for $24 \mathrm{~h}$. The difference in the measured weights was then divided by the sample volume $\left(\mathrm{mm}^{3}\right)$ as follow [10]:

$$
p=1-\left(\frac{\frac{w_{1}-w_{2}}{\rho_{w}}}{v}\right) \times 100
$$

where $p$ is the total porosity of the PC (\%), $w_{1}$ is the PC sample weight air-dried for $24 \mathrm{~h}(\mathrm{~kg}), w_{2}$ is the PC sample weight submerged under water $(\mathrm{kg}), v$ is the PC sample volume $\left(\mathrm{mm}^{3}\right)$, and $\rho_{w}$ is density of water $\left(\mathrm{kg} / \mathrm{mm}^{3}\right)$.

\section{Results and Discussion}

\subsection{Porosity and Permeability Coefficient}

Table 3 shows the measured properties of all PC mixes, including permeability coefficient and porosity. Average results from the experimental research were summarized in this table. The tests yielded a range of values from about $8 \mathrm{~mm} / \mathrm{s}$ to $15.1 \mathrm{~mm} / \mathrm{s}$ for permeability coefficient. It can be seen from Table 3 that the highest permeability coefficient achieved in this study is $15.1 \mathrm{~mm} / \mathrm{s}$ for mixture CPC1, which was produced from coarse aggregate. Mixture FPC4 has the lowest permeability coefficient of $8 \mathrm{~mm} / \mathrm{s}$, which was produced from fine aggregate. The density of PC is approximately $1800 \mathrm{~kg} / \mathrm{m}^{3}$.

Figure 3 illustrate the effect of porosity on permeability coefficient for CPC. Although there is a notable scatter in the plotted data, the permeability coefficient generally increases when the porosity increases. Figure 4 illustrate the effect of porosity on permeability coefficient for FPC.

The highest permeability coefficient of around $15.1 \mathrm{~mm} / \mathrm{s}$ can be seen when the porosity is higher than $41 \%$. The smallest permeability coefficient of around $8 \mathrm{~mm} / \mathrm{s}$ can be seen when the porosity is higher than 35\%.

\begin{tabular}{ccccc}
\multicolumn{6}{l}{ Table 3. Measured data of all PC mixes. } \\
\hline Pc mixtures & Size of Aggregates $(\mathrm{mm})$ & w/c & Porosity & Permeability Coefficient $(\mathrm{mm} / \mathrm{s})$ \\
\hline FPC1 & 9.5 & 0.28 & 0.39 & 11.3 \\
FPC2 & 9.5 & 0.3 & 0.386 & 10.5 \\
FPC3 & 9.5 & 0.32 & 0.375 & 9.5 \\
FPC4 & 9.5 & 0.34 & 0.35 & 8 \\
CPC1 & 19.5 & 0.28 & 0.41 & 15.1 \\
CPC2 & 19.5 & 0.3 & 0.405 & 14.5 \\
CPC3 & 19.5 & 0.32 & 0.4 & 14 \\
CPC4 & 19.5 & 0.34 & 0.39 & 12.5 \\
\hline
\end{tabular}




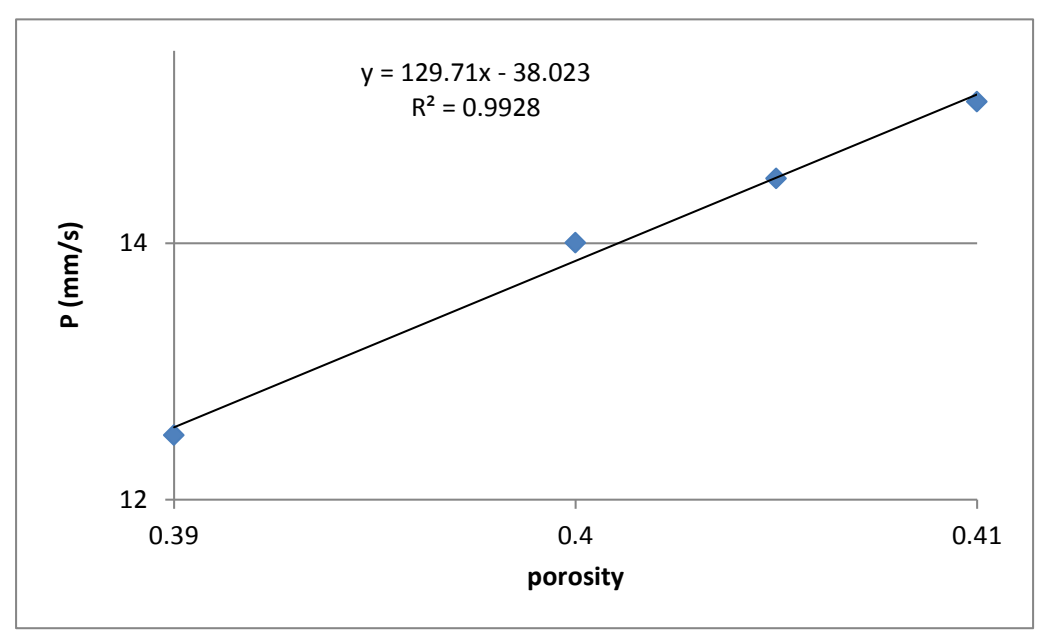

Figure 3. Effect of porosity on permeability coefficient for CPC.

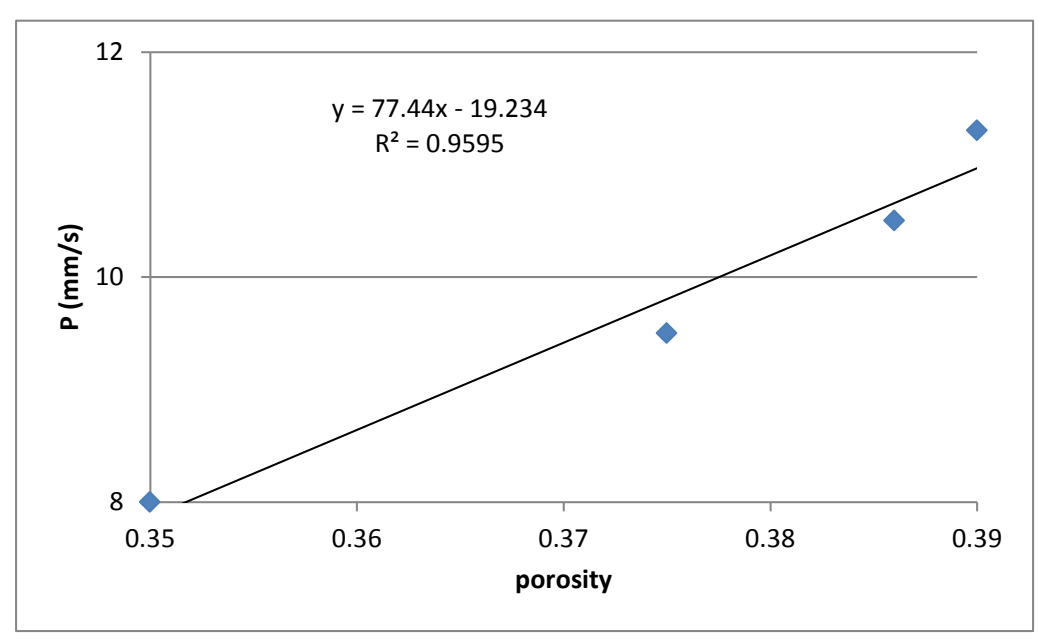

Figure 4. Effect of porosity on permeability coefficient for FPC.

These Figures show that porosity played an important role in the PC specimen permeability coefficient. These changes can be mainly attributed to the decrease in workability of the mix designs as the W/C is adjusted. Traditional methods of measuring the workability of a PC mix are not effective for mixes, as they generally have negligible slump even when the W/C is below the optimal level. With increased workability, greater densification occurs even when and porosity decreased. This greater densification led to decrease in permeability that was observed for the various mix designs.

\subsection{Effect of W/C and Aggregate Size}

Figure 5 and Figure 6 show the effect of W/C on permeability coefficient for FPC and CPC. The highest permeability coefficient achieved in this study is $15.1 \mathrm{~mm} / \mathrm{s}$ for mixture CPC1. Mixture FPC4 has the lowest permeability coefficient of $8 \mathrm{~mm} / \mathrm{s}$. Results indicated that reduction in permeability coefficient caused by size of aggregate was more than that by W/C. Results show good relationship between permeability coefficient and W/C, supporting the conclusion that greater workability leads to a denser specimen with smaller permeability coefficient. Lab mixes had the highest permeability coefficient, had the lowest W/C.

\section{Statistical Analysis of the Results}

Analysis of variance (ANOVA) was used to test the significance of regression models, and t-test were performed to identify the non-significant (NS) variables model coefficients. 


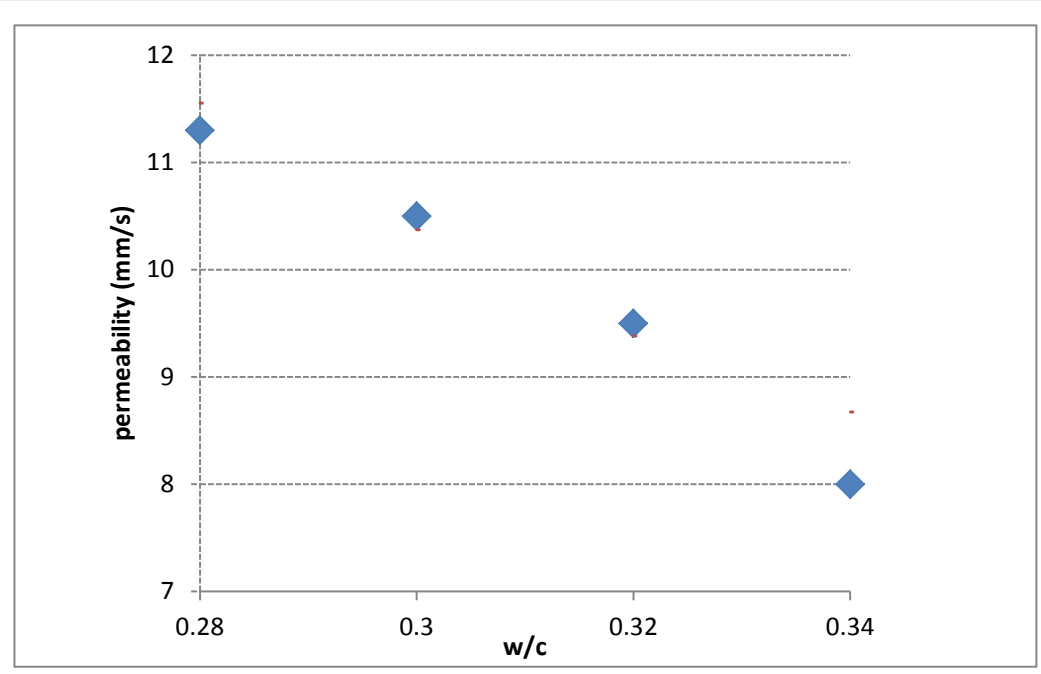

Figure 5. Effect of W/C on permeability coefficient for FPC.

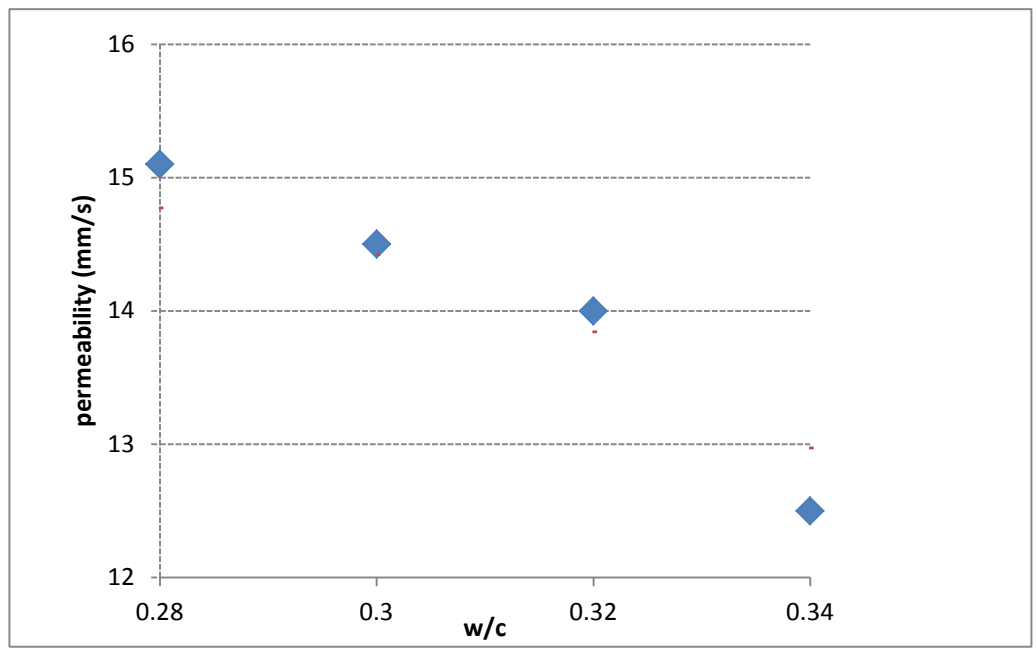

Figure 6. Effect of W/C on permeability coefficient for CPC.

A regression model (RM) along with ANOVA was conducted to study the significance of porosity distribution on PC permeability coefficient, as follow: Permeability Coefficient $=$ Constant $+\mathrm{A} \times$ Porosity

Where, A is regression multiplier.

The statistical analysis parameters for FPC are shown in Table 4 and for CPC is shown in Table 5 indicates that for permeability coefficient of PC samples, the porosity of all samples included in this study are significant with a R-Squared values of $95 \%$ and $98 \%$. The analysis also indicates that the increase of porosity content increased the permeability coefficient, as the multiplier sign is positive.

This model could be used to estimate the permeability coefficient for any porosity included in the regression model, however, it is limited to the specific size of aggregate used in this study.

\section{Summary and Conclusions}

In this study, the main property of PC containing two aggregate sizes was investigated. Twenty-four (24) different mixes of PC were tested. The experimental investigations included determining porosity, permeability, and relationships among them. The W/C and aggregate size had an effect on the hydrological properties like permeability coefficient and porosity. RM revealed good relationships between porosity and permeability coefficient. The models can be used to simulate the influence of porosity on the permeability coefficient of PC. The main conclusion remarks are summarized below: 
Table 4. RM parameters for permeability coefficient of FPC.

\begin{tabular}{ccccc}
\hline Factor & Multiplier Estimate & Standard Error & T test & R squared \\
\hline Constant & -19.2 & 4.23 & -4.6 & \multirow{2}{*}{0.96} \\
A & 77.4 & 11.25 & 6.88 & \\
\hline
\end{tabular}

\begin{tabular}{ccccc}
\multicolumn{6}{l}{ Table 5. RM parameters for permeability coefficient of CPC. } \\
\begin{tabular}{ccccc}
\hline Factor & Multiplier Estimate & Standard Error & T test & R squared \\
\hline Constant & -38 & 3.14 & -12.1 & 0.99 \\
A & 130 & 7.84 & 16.56 & \\
\hline
\end{tabular}
\end{tabular}

1) The average density of PC was around $1800 \mathrm{~kg} / \mathrm{m}^{3}$ with a porosity of $37 \%$, depending on the mix design.

2) The average water permeability coefficient of PC produced from single sizes aggregate is approximately 10 $\mathrm{mm} / \mathrm{s}$ for FPC and $14 \mathrm{~mm} / \mathrm{s}$ for CPC. These values depend on the mix design.

3) As expected, if the W/C of PC increased, the porosity and water permeability coefficient decrease. W/C played a strong role in both the permeability coefficient and porosity of PC.

4) Characteristics such as permeability coefficient and porosity showed clear dependence on the size of aggregates and mix design parameters.

5) The RM indicates that for permeability coefficient of PC samples, the porosity is significant with RSquared values of $96 \%$ and $99 \%$.

\section{Acknowledgements}

The authors gratefully acknowledge the support given by the laboratory team of Tarbiat Modares University for their help to complete the laboratory tests and data collection.

\section{References}

[1] Vassilikou, F., Kringos, N. and Kotsovos Scarpes, A. (2011) Application of Pervious Concrete for Sustainable Pavements: A Micro-Mechanical Investigation. TRB 90th Annual Meeting, Washington DC, 23-27 January 2011, 11-0695.

[2] Lian, C. and Zhuge, Y. (2010) Optimum Mix Design of Enhanced Permeable Concrete-An Experimental Investigation. Construction and Building Materials, 24, 2664-2671. http://dx.doi.org/10.1016/j.conbuildmat.2010.04.057

[3] Vancura, M., Mc Donald, K. and Khazanovich, L. (2011) Microscopic Analysis of Paste and Aggregate Distress in Pervious Concrete in a Wet, Hard Freeze Climate. Cement and Concrete Composites, 33, 1080-1085. http://dx.doi.org/10.1016/j.cemconcomp.2011.05.011

[4] Sumanasooriya, M.S. and Neithalath, N. (2011) Pore Structure Features of Pervious Concrete Proportioned for Desired Porosities and Their Performance Prediction. Cement and Concrete Composites, 33, 778-787. http://dx.doi.org/10.1016/j.cemconcomp.2011.06.002

[5] Suozzo, M. and Dewoolkar, M. (2012) Long-Term Field Monitoring and Evaluation of Maintenance Practice of Pervious Concrete Pavements in Vermont. TRB 91st Annual Meeting, 2292. http://dx.doi.org/10.3141/2292-12

[6] Shu, X., Huang, B., Wu, H, Dong, Q. and Burdette, E.G. (2011) Performance Comparison of Laboratory and Field Produced Pervious Concrete Mixtures. Construction and Building Materials, 25, 3187-3192. http://dx.doi.org/10.1016/j.conbuildmat.2011.03.002

[7] Boyer, M., Haselbach, L. and Cofer, W. (2012) Heat Transfer Finite Element Modeling in Pervious Concrete: Impacts of Vertical Porosity Distributions. TRB 91st Annual Meeting, Washington DC, 22-26 January 2012, 12-1241.

[8] Shen, S., Burton, M., Jobson, B. and Haselbach, L. (2012) Pervious Concrete with Titanium Dioxide as a Photo Catalyst Compound for a Greener Urban Road Environment. TRB 91st Annual Meeting, Washington DC, 22-26 January 2012.

[9] Tho-in, T., Sata, V., Chindprasirt, P. and Jaturapitakkul, C. (2012) Pervious High-Clacium Fly Ash Geopolymer Concrete. Construction and Building Materials, 30, 366-371. http://dx.doi.org/10.1016/j.conbuildmat.2011.12.028

[10] ASTM Standard C 192. (2012) Standard Practice for Making and Curing Concrete Test Specimens in the Laboratory Concrete, Cylinders, Laboratory, Prisms, Strength Testing. ASTM International, West Conshohocken, PA.

[11] Park, S.-B. and Tia, M. (2004) An Experimental Study on the Water-Purification Properties of Porous Concrete. Cement and Concrete Research, 34, 177-184. http://dx.doi.org/10.1016/S0008-8846(03)00223-0 